\title{
Heatwaves and Health Risks in The Northern Part of Senegal: Analysing The Distribution of Temperature Related Diseases and Associated Risk Factors
}

ibrahima Sy ( $\square$ ibrahima.ousmane.sy@gmail.com )

Cheikh Anta Diop University: Universite Cheikh Anta Diop https://orcid.org/0000-0002-3266-1001

Birane Cissé

Cheikh Anta Diop University: Universite Cheikh Anta Diop

Babacar Ndao

Centre de Suivi Ecologique (CSE)

Mory Touré

Cheikh Anta Diop University: Universite Cheikh Anta Diop

Abdoul Aziz Diouf

Centre de Suivi Ecologique (CSE)

Mamadou Adama Sarr

Gaston Berger University: Universite Gaston Berger

Ousmane Ndiaye

Agence Nationale de l'Aviation Civile et de la Météorologie (ANACIM)

Youssoupha Ndiaye

Ministère de la Santé et de la Prévention: Ministere de la Sante et de l'Action Sociale

Daouda Badiane

Universite Cheikh Anta Diop de Dakar

Richard Lalou

Institut de recherche pour le développement: Institut de recherche pour le developpement

Serge Janicot

Institut de recherche pour le développement: Institut de recherche pour le developpement Jacques-André Ndione

Centre de Suivi Ecologique (CSE)

\section{Research Article}

Keywords: climate, temperature, heatwaves, diseases, health risks, Senegal.

Posted Date: February 22nd, 2022

DOl: https://doi.org/10.21203/rs.3.rs-1098485/v2 
License: (c) (i) This work is licensed under a Creative Commons Attribution 4.0 International License. Read Full License 


\section{Abstract}

Backgrond: The Sahelian zone of Senegal is marked by heatwave events due to temperatures increase especially in 2013 exceeding $45^{\circ} \mathrm{C}$ with an impact on morbidity and mortality rise. In order to document health impacts of recurrent extreme temperatures in this part of the country, a study was carried out combining heatwaves detection, occurrence of climate-sensitive diseases and risk factors for exposure.

Methods: To do this, a set of climatic (temperatures) and health (morbidity, mortality) data were collected for April, May and June season from 2009 to 2019. These data were complemented by surveys on exposure risk factors of 1246 households. Statistical methods were used to carry out univariate and bivariate analyzes while cartographic techniques allowed visualization of the main climatic and health indicators.

Results: The results show an increase in temperatures compared to seasonal normal for the 1971-2000 reference period with threshold exceedances of the 90th percentiles $\left(42^{\circ} \mathrm{C}\right)$ for the maxima and $\left(27^{\circ} \mathrm{C}\right)$ the minima and higher temperatures during the months of May and June. From health perspective, it was noted an increase in cases of consultation on health facilities as well as a rise in declared morbidity by households especially in the departments of Kanel (17.7\%), Ranérou (16.1\%), Matam (13.7\%) and Bakel (13.7\%). The heatwaves of May 2013 were also associated with cases of death with a reported mortality (observed by medical staff) of $12.4 \%$ unevenly distributed according to the departments with a higher number of deaths in Matam (25, 2\%) and in Bakel (23.5\%) than in Podor (8.4\%) and Kanel (0.8\%). The morbidity and mortality distribution according to gender shows that women (57\%) were more affected than men (43\%). These health risks have been associated with a number of factors including age, access to drinkable water, type of fuel, type of housing and construction materials, existence of fan, an air conditioner, health antecedents, etc.

Conclusion: The heatwaves recurrence has led to an upsurge in certain diseases sensitive to rising temperatures, which is increasingly a public health issue in the Sahelian zone of Senegal.

\section{Introduction}

In the context of global climate warming marked by temperatures increase, particularly in the Sahel strip, heat waves events are becoming a serious public health threat with the absence of effective adaptation measures (Huang,et al., 2010 ; Benmarhnia et al., 2014 ; Murari et al., 2015 ; Guo et al., 2016 ; Baaghideh \& Mayvaneh, 2017). With a predicted rise in global temperature from 1 to $6^{\circ} \mathrm{C}$ by 2100 , the risk of extreme weather events such as heat waves will increase, and greatly affect Sahel territories (Kovats \& Kristie, 2006 ; Fouillet et al., 2006; Christensen et al., 2007; Smith et al., 2014; WMO, 2015). In contrast to developed countries, heat wave episodes and their impacts on population health are still poorly documented in this area where the number of hot days and nights is constantly increasing (Basu \& Samet, 2002 ; Johnson et al., 2005; IPCC, 2007; Smith et al., 2013 ; Li et al., 2015 ). In the northern part of Senegal, temperatures are expected to rise between $1.1^{\circ} \mathrm{C}(\mathrm{RCP} 4.5)$ and $1.3^{\circ} \mathrm{C}(\mathrm{RCP} 8.5)$ in 2015 , while 
climate projections indicate an increase of $2^{\circ} \mathrm{C}$ by 2040 and $3^{\circ} \mathrm{C}$ by 2100 . The most pessimistic scenarios indicate a temperature increase about $4^{\circ} \mathrm{C}$ by 2050 (MEDD-GCF, 2020). In the African Sahel belt, reported heat waves events date back to 2000 with high temperatures reaching $50^{\circ} \mathrm{C}$ around 19 April in Niamey, with an almost similar situation in Senegal, Mali, Burkina-Faso and Chad during the same period. Other parts of the African continent are also affected by extreme temperature events with $51.3^{\circ} \mathrm{C}$ in Ouargla and $49.6^{\circ} \mathrm{C}$ in Touggour in Algerian Sahara and $49.2^{\circ} \mathrm{C}$ in Tozeur and $48.3^{\circ} \mathrm{C}$ Kairouan in Tunisia during July 2018 (Carlton et al., 2016; Guo et al., 2018).

Heat waves events have been associated with excess of mortality and morbidity which often affect young children, people suffering from chronic diseases and the ageing population (Armstrong, 2006 ; Elliot et al., 2013; Zacharias et al., 2014; Auger, 2015; Chen, 2016). A historical review of some past events provides a good context of health risks associated with heat waves. In the city of Chicago in USA, a large part of the ageing population was affected by rising temperatures, with 365 deaths recorded during the summer of 1995 (Naumova et al., 2007). In France, the heat wave recorded during the summer of 1983 led to the death of several elderly people, with more than 300 deaths reported in the city of Marseille (Cadot, 2006; Fouillet, 2006). The terrible heat wave of 2003 was particularly lethal with more than 15,000 deaths reported in France (Besancenot, 2005; Vandentorren et al., 2003). The occurrence of heat waves in July 2018 in the northern hemisphere, which lasted seven (07) days, was marked by excess of mortality with 70 deaths in Canada and 35,000 people hospitalized and 80 deaths in Japan. In 2013, the Sahelian region located between Senegal, Mauritania and Mali experienced an exceptional heat wave with a temperature which exceeded $45^{\circ} \mathrm{C}$ and lasted from May 23 to 27 (i.e., 5 days). This event had a considerable impact on the population health. During this heat wave episode, localities in northern Senegal recorded 27 cases of death reported and confirmed by the health districts.

These observations show a generalization of heat wave events at the planetary level, hence an international mobilization on issues related to the temperatures increase is considered as a health priority issue. The major findings based on peer review litterature dealing with heat wave events over America and Europe have demonstrated that the impact of extreme temperatures on human health is a reality in terms of excess of mortality and morbidity recorded. In Africa, however, the health impact of heat waves is still little known due to the lack of scientific work on this phenomenon, while in some geographical areas such as the Sahel, high rates of extreme temperatures are often recorded (Musengimana et al., 2016). Thus, as part of a research project of Sahelian Heatwaves Alert and Health Impacts (ACASIS) funded by the French National Research Agency (ANR) and implemented by the French Research Institute for Development (IRD) and its scientific partners, a series of field surveys were carried out between 2016 and 2018 in departments of the northern part of Senegal located on the Sahelian belt which is more affected by heat wave episodes. The purpose of these studies was to scientifically document the effects of the extreme temperatures recurrence on communities health in this part of the country, with a particular emphasis on the detection of heat wave indices, the evolution of linked climate diseases and climate vulnerability factors such as the practices and behaviours of populations facing abnormally high temperatures during the months of April-May-June and the socio-economic, environmental and cultural characteristics of households. Thus, the rising temperatures are a major driver of health status 
deterioration of communities; the relationships between (i) the recurrence of heat wave episodes, (ii) excess of morbidity/mortality and (iii) the exposure factors involved in modulating the vulnerability of populations against this type of health risk, were analyzed in the present study.

\section{Material And Methods \\ 2.1. Study area}

The study was implemented in the Northern and North-Eastern part of Senegal and covers the departments of Dagana, Podor, Louga, Linguère, Matam, Ranérou, Kanel and Bakel located in the regions of Saint-Louis, Louga, Matam and Tambacounda (figure 1). This area considered is the most affected one by heat waves in Senegal has an estimated population of 1,928,962 inhabitants (ANSD, 2013). The averaged population density, often very low, is about 30 inhabitants per $\mathrm{km}^{2}$ due to a strong migration towards coastal urban centres. The majority of the resident population are often elderly peoples, women and children.

The climate characteristic is continental Sahelian type with two seasons: a rainy season (JulySeptember) and a dry season (October-June). After three decades of drought, wet periods are back in this area since the early 2000s, even if rainfall total is generally low, varying between 200 and 400 millimetres per year. Temperatures in this area are among the highest in Senegal, with annual averages around $30^{\circ} \mathrm{C}$ and maxima sometimes exceeding $45^{\circ} \mathrm{C}$. These particular climatic conditions that characterise the study area do not enable the development of dense vegetation and the presence of permanent watercourses which can lead to a micro-climate conditions.

\subsection{Data collection}

\subsubsection{Temperature data}

The temperature data were obtained from ANACIM weather stations in the departments of Louga, Linguère, Podor, Matam and Bakel. These are ambient temperatures in the areas polarized by health structures in the study area. These data were supplemented by data from climate model outputs for the departments of Dagana, Ranérou and Kanel without meteorological stations. The variables used to analyse the impact of heat wave episodes on population health in the study are relative to the maximum, average and minimum temperatures during the hottest months of April, May and June for the period 2009 to 2019. The choice of these variables for the correlation analysis between heat wave episodes and health risks was motivated by the scientific need to document and analyse the relationship between heat wave episodes and health risks in terms of excess of morbidity and mortality.

\subsubsection{Epidemiological data from health facilities}

Health data were collected on the basis of the prior definition of a list of diseases considered as linked to climate-variability (i.e., arterial hypertension, diarrhoea, asthma, colds and coughs, acute respiratory 
infection, diabete, kidney problems, heart problems, joint pain and skin irritations). This list was defined through the precise and clear identification of clinical signs and symptoms (fevers, headaches, body pain, heat stroke, exhaustion, dehydration, syncope and hyperthermia) associated with the physiological state of the patients in consultation during periods of rising temperatures.

The health data collection was carried out for the months considered to be the hottest (April-May-June) from 2009 to 2019.

The collected data comes from two sources: (i) the National Health Information System « SNIS » via the DHSI2 (District Health Information Software) platform of the Ministry of Health and Social Action and (ii) the use of information from patient consultation registers using a collection form provided by the health centres of the departments of Louga, Linguère, Dagana, Podor, Ranérou, Matam, Kanel and Bakel. The variables recorded were the date of consultation, age, sex, place of residence, clinical signs or symptoms, the pathology diagnosed, the treatment prescribed, etc. These informations were then used to determine the patient's health status and the cause of consultation.

\subsubsection{Socio-economic, environmental and health surveys among households}

These quantitative and qualitative cross-sectional surveys were carried out with the help of the Health Districts professionals in the target departments between 2015 and 2017. These household surveys were designed to highlight the factors of exposure and vulnerability to the heat waves health impacts. They involved households in the departments that agreed to participate by signing the informed consent form. The information collected by means of a questionnaire covered the following topics: demographic and socio-economic characteristics, knowledge of climate change and climate risks, identification of clinical signs or symptoms associated with climate-sensitive diseases, morbidity and mortality of the target pathologies, access to health care, factors of exposure and vulnerability to the health impacts of heat waves, adaptation behaviours and practices.

The sample size was determined using the National Agency for Statistics and Demography (ANSD) database, which provides estimates of 13,306 households in the study area. By applying a confidence level of $90 \%$ and a margin of error of $5 \%$, the sample size was 1,331 households to be surveyed for the entire target area. For the sample spatial distribution, a two-stage stratified survey was carried out based on a stratification of the different departments according to specific demographic, socio-economic and environmental characteristics. In each stratum of departments, five villages were selected, three of which were in urban areas and two in rural areas. In the selected villages, the proportion of households to be interviewed in the overall sample was calculated in proportion to the percentage of the number of households present in the locality. The method used to select the households to be surveyed was done randomly with a time step of ten (10) concessions. The questionnaire was submitted to the head of household or persons designated by him to answer the questions. Out of an initial planned sample of 1,331 households targeted for the study, only 1,246 were surveyed due to different reasons such as the inaccessibility of the village and unavailability of respondents. 


\subsection{Data processing and analysis}

The processing of the collected data led to the identification of indicators related to heat waves associated to health effects, the epidemiology of climate-sensitive diseases and the associated risk factors. The temperature and health data collected were statistically analysed using different data processing software such as SPSS, R, Stata, XLStat and Arcgis. For the data analysis on perceived morbidity, it should be noted that only 1,119 questionnaires for which information on the symptoms described by the respondents corresponded to the clinical signs of climate-sensitive diseases were taken into account in the statistical analyses.

The temperature data (maximum, minimum and average) were analysed on the basis of the ANACIM 1971-2000 normal, the three-day temperature threshold exceedance of the 90th percentiles (IPCC, 2007) and the definition of heat wave indices as part of ACASIS project. Daily maxima observation and daily mean maxima temperatures were considered to define a heat wave period that takes into account the threshold of the 97.5 and 81th percentile of the maximum temperature distribution (Huth, 2000). These indices of heat waves and temperature threshold exceedances (maximum, minimum and average) compared to the seasonal normal were used to identify trends in temperature anomalies and highlight the years during which the months of April, May and June are the warmest for the period 2009-2019 in this part of Senegal. These analyses provided a series of temperature curves and maps that enabled to select three years during which the months of April, May and June were warmer.

Epidemiological data on climate-sensitive diseases (diagnosed morbidity) were analysed by applying descriptive statistical methods (dynamic cross-tabulation) to determine their prevalence in overall morbidity and mortality but also their distribution according to the different departments, age and sex of patients affected by the pathologies concerned for the months of April, May and June of the period 20092019. Cross-analyses in the form of correlative evolution curves between the temperature variables (maxima, minima, averages) for the months of April, May and June and the evolution of the number of consultations and deaths for climate-sensitive diseases were carried out to highlight the association between heat waves and health risks. The results of these analyses are presented in the form of graphs and maps.

Data on the perceived morbidity and mortality of temperature related diseases from household surveys were first analysed using descriptive statistical methods (dynamic cross-tabulation) to determine their prevalence in overall morbidity and mortality rate but also their distribution according to the different departments, age and sex of patients affected by the diseases concerned. Factorial and correlative statistical analyses were then carried out between the prevalence of perceived morbidity and the various risk factors identified (socio-demographic, economic, environmental and cultural variables) by carrying out Chi-2 (Fischer/Pearson) tests, logistic regression with Odds Ratios (OR) and 95\% confidence intervals and a correlation matrix between different dependent variables.

\section{Results}




\subsection{Evolution of temperatures and heat waves in the northern part of Senegal}

In temperature data analysis for the months of April, May and June from 2009 to 2019, the occurrence of heat waves was considered when there is a 90 th percentile threshold exceedence of $42^{\circ} \mathrm{C}$ for maximum temperatures and $27^{\circ} \mathrm{C}$ for minimum temperatures. Overall, it was observed a global increase trend in maximum and minimum temperatures compared to the seasonal normal for the reference period 19712000. Exceedances of the 90 th percentile threshold $\left(42^{\circ} \mathrm{C}\right)$ for maximum and minimum temperatures $\left(27^{\circ} \mathrm{C}\right)$ were recorded everywhere except in the departments of Louga $\left(38.5^{\circ} \mathrm{C}\right)$ and Dagana $\left(38.8^{\circ} \mathrm{C}\right)$. For both maximum and minimum temperatures, the months of May and June were considered as the hottest periods of the year affecting more the departments of the continental Sahel (Bakel, Matam, Kanel, Ranérou, Linguère and Podor) (Figure 2). The monthly heat wave distribution shows that May appears as the hottest with variations of more than $6.6^{\circ} \mathrm{C}$ in 2009 in Podor compared to the period 1971-2000 and record heat waves in 2010 and 2013 for maximum temperatures. Compared to the seasonal normal, the year 2010 was considered as the hottest with more than 250 heat wave events recorded with a higher frequency in the departments of Ranérou, Matam, Kanel and Bakel. Since 2016, there has been an upward trend in heat wave events often exceeding the threshold of 100 events in the year, especially in 2016, 2017 and 2019 (Figure 2a). However, the different heat wave events recorded from 2009 to 2019 do not have the same intensity everywhere with regard to the lower maximum and minimum temperatures observed (between 30 and $39^{\circ} \mathrm{C}$ ) in Louga, which certainly benefits from the effect of the maritime and oceanic domain (figure 3 ).

\subsection{Distribution of morbidity and mortality of heatwave- sensitive diseases}

The spatial distribution of morbidity diagnosed from 2009 to 2019 of diseases sensitive to the rise in temperatures for the months of April, May and June shows a higher number of consultation cases in the departments of Matam (44,514 cases), Kanel (41,655 cases) and Bakel (41,204 cases) while this proportion is lower in Linguère ( 10,588 cases), Louga ( 21,527 cases) and Dagana ( 23,476 consultation cases) with a predominance of the female gender (figure 4). For the three months considered, the distribution according to type of disease shows that diarrhea is the most represented in global pathology. The global distribution of the morbidity diagnosed nearly obeys the same dynamic as that reported for 2013 , with more than $12.5 \%$ of the households surveyed declaring that they had experienced morbid episodes (769 cases) during the heat wave period (figure 5). Indeed, households that declared cases of morbidity are more represented in the departments of Kanel (17.7\%), Ranérou (16.1\%), Matam (13.7\%) and Bakel (13.7\%), while this proportion is relatively lower in Linguère (7.8\%) and Podor (8.5\%). The gender distribution of affected population during the May 2013 heat wave shows that women $(57 \%)$ were more affected than men (43\%). The occurrence of heat waves in May 2013 was associated with cases of death reported by the households surveyed, and had particularly affected elderly women (figure 6). However, reported mortality (confirmed by health professional) of $12.4 \%$ (119 cases) is also unevenly 
distributed across the departments with more households reporting deaths noted in Matam (25.2\%), Bakel (23.5\%), Dagana (22.7\%) and Louga (10\%) than in Linguère (9.2\%), Podor (8.4\%) and Kanel (0.8\%). The spatial distribution of reported morbidity is almost proportional to the distribution of reported mortality according to the departments except for Dagana where the rate of households that registered occurrence of morbid episodes is lower than the number of reported deaths.

\subsection{Relationships between heatwaves and morbidity of temperature-sensitive diseases}

The analysis results of the association between the temperatures evolution for the months of April, May and June and the cumulative of temperature related pathologies show a growing increase in consultations in health centres from the years during which heat waves began to be more recurrent. The care use due to temperature-sensitive diseases was very high during the years 2013, 2015, 2017 and 2018 in the departments of Ranérou, Bakel, Podor and Louga in correlation with the occurrence of heat wave episodes, particularly during the month of May (figure 7). In the department of Bakel, where 2015 was considered as a heat waves year, there was an increase in consultations for the six (06) diseases considered to be sensitive to temperature changes. Similarly, in both Louga and Podor, there was a significant increase in the number of consultations in health centres during 2016 and 2017, considered to be the hottest years. In the district of Ranérou, it was correlated with a very high number of health facilities visits from 2014 to 2018, a period during which there was a significant increase in temperatures, particularly the maxima. Overall, the upward trend in the frequency of heat waves and the evolution of the number of consultations for the six (06) climate-sensitive diseases highlights the impact of temperatures on health facilities visits.

\subsection{Exposure and vulnerability risk factors to health impacts of heat waves}

Exposure and vulnerability to the health impacts of heatwaves are influenced by a number of risk factors (Table 1). The age of persons has been identified as an exposure risk factor to the effects of heat waves, which affect more people over 61 years old and children and adolescents under 20 years old. This risk factor is often aggravated by having a medical background including chronic diseases such as high blood pressure, epilepsy, diabetes, heart disease or asthma which more affect the elderly. The majority of those affected had symptoms associated with the onset of heat waves such as hyperthermia, headaches, tiredness body, fainting or dizziness. Access problem to safe drinking water was also analyzed as an exposure factor to health impacts of heat waves. Households with a tap at home are less exposed to the effects of increasing temperature than those who move to get water from standpipes (91\%) or wells (86\%) (figure 8). The type of fuel used is also an exposure risk factor to temperature-sensitive diseases. The results of the analyses show that people living in households using wood (85\%) or charcoal (85\%) are more affected than those using butane gas (figure 4: b). The kitchen location was also an exposure factor to health risk related to heat waves. Indeed, women cooking open air are much more at exposure 
risk to effects of heat waves than those whose kitchen is located in housing inside (figure 8). The type of housing and building materials were identified as risk factors for diseases related to heat waves. People living in huts and straw huts are less exposed to the temperature effects than those living in low-rise $(76 \%)$ or multi-storey $(80 \%)$ houses (figure 8$)$. For building materials, people living in straw or wooden houses are less exposed than those living in solid or banco-built housings (figure 8 ). The availability of household equipment such as a fan or air conditioner was analysed as a mitigation factor of heat waves effects. The analyses demonstrated that people living in households with a fan or air conditioner are less exposed to heat effects compared to those without such equipment (figure 8).

Table 1

Vulnerability risk factors of households to heatwaves

\begin{tabular}{|c|c|c|c|c|c|c|c|}
\hline Risk factors & Coef. & Std. Err. & z & $P>z$ & {$[95 \%$} & Conf. & Significance \\
\hline Gender person & -.6504591 & .1605448 & -4.05 & 0.000 & -.965121 & -.3357972 & $* * *$ \\
\hline $\begin{array}{l}\text { Household } \\
\text { population } \\
\text { density }\end{array}$ & .1103047 & .0490329 & 2.25 & 0.024 & .014202 & .2064075 & * \\
\hline $\begin{array}{l}\text { Type of } \\
\text { housing used }\end{array}$ & -.6888186 & .1745533 & -3.95 & 0.001 & -1.030937 & -.3467005 & *** \\
\hline $\begin{array}{l}\text { Housing } \\
\text { material } \\
\text { construction }\end{array}$ & .3784948 & .1907388 & 1.98 & 0.003 & .0046536 & .752336 & $* * *$ \\
\hline $\begin{array}{l}\text { Type of energy } \\
\text { used }\end{array}$ & .5459268 & .2305418 & 2.37 & 0.018 & .0940732 & .9977804 & * \\
\hline $\begin{array}{l}\text { Household } \\
\text { water } \\
\text { avalaibility }\end{array}$ & .046807 & .2048986 & 0.23 & 0.010 & -.3547868 & .4484008 & * \\
\hline $\begin{array}{l}\text { Fan or air } \\
\text { conditioner } \\
\text { avalaibility }\end{array}$ & -.3625368 & .1803599 & -2.01 & 0.000 & -.7160357 & -.0090378 & *** \\
\hline $\begin{array}{l}\text { Type of fuel } \\
\text { used in } \\
\text { household }\end{array}$ & .7673144 & .1763332 & 4.35 & 0.000 & .4217077 & 1.112921 & $* * *$ \\
\hline $\begin{array}{l}\text { Previous and } \\
\text { chronic health } \\
\text { problems }\end{array}$ & 1.685009 & .217815 & 7.74 & 0.006 & 1.2581 & 2.111919 & ** \\
\hline
\end{tabular}

\section{Discussion}

Like the countries located in temperate latitudes, which are increasingly affected by recurrent heat wave phenomena, the Sahelian tropical areas are frequently affected by a generalized trend of warming temperatures (Green et al., 2010; Guo et al., 2018). In Senegal, the north-eastern part of the country is particularly affected by the recurrence of heat waves, with significant variations of temperatures 
compared to the $1971-2000$ normal ranging from $-2^{\circ} \mathrm{C}$ to $+3^{\circ} \mathrm{C}$. The ratio between the inter-annual variability and the normal of 1971-2000 shows a considerable increase in maximum and minimum temperatures with a very significant positive variation of $2.5^{\circ} \mathrm{C}$ for 2013 in the Northern localities of Senegal. Very high maximum temperatures exceeding the threshold of $46^{\circ} \mathrm{C}$ and a variation of more than $7^{\circ} \mathrm{C}$ for some days during the month of May 2013 have been reached compared to the normal of 19712000.

Thus, the occurrence frequency of heat waves is increasingly becoming a major public health issue in the Senegalese context, in particular since the results of the study showed that the gradual increase in temperatures up to around $39^{\circ} \mathrm{C}$ resulted in a surplus of 45 patients in health centres and an excess mortality of nearly 25 people during hot days, in particular in the departments of Matam, Bakel, Dagana and Louga (Diboulo, 2012; Petkova, 2013; Zhang, 2014). According to clinical examinations during the heat wave periods, the symptoms presented by the patients were hyperthermia, headaches, tiredness, fainting or dizziness, while the pathologies diagnosed were mainly chronic diseases such as high blood pressure, epilepsy, diabetes, cardiovascular diseases, respiratory infections, diarrhoea and asthma (Semenza et al., 1995 ; Pascal et al., 2013; Smith et al., 2016 ; Sanderson et al., 2017).

However, the distribution of heat-wave-related diseases varies widely by location, age, gender and risk factors. Indeed, the departments located in the North-Eastern part of the country, which are Matam, Ranérou, Kanel and Bakel, concentrate the populations that are most exposed to the health risks related to heat waves occurrence. As demonstrated in other countries in Europe, Asia and America, people over 61 years and the infant and child fringe are the most vulnerable to the health impacts related to the rise in temperatures in the most affected departments (Jones et al., 1982; Semenza et al. 1996; Hémon et al., 2003; Pascal et al., 2005; Hémon et al., 2005). Older people are exposed through the prism of co-morbidity to chronic diseases considered as the aggravating health background of heat waves effects (Nitschke, 2013). Regarding children, increasing temperatures amplify the spread of childhood illnesses, especially those that cause dehydration, in a group consisting mainly of schoolchildren who, in these localities, walk long distances to reach their schools, whose descent (12 to 13 hours) and recovery (14 to 15 hours) times correspond to period of extreme heat peaks (Xu et al., 2012). According to gender, women engaged in extra-domestic activities, such as fetching water, searching firewood and agro-pastoral activities that require them to travel long distances under the sun, are the most exposed to heat waves effects, especially since there are no early warning systems to prevent risks associated with increasing temperatures (Xu et al., 2016).

Furthermore, analyses have shown that the degree of vulnerability to heat wave-related health risks is the result of a range of risk factors including the type of housing, building materials, human density in households, access to water, type of used fuel, location of kitchen, access to ventilation or air conditioning, existence of relaxation areas, health history, etc. In numerous studies carried out in similar heat wave situations, such risk factors were highlighted in the occurrence of pathologies linked to rising temperatures (Michelozzi et al., 2010; Cheng et al., 2014; Anderson et al., 2016). However, heat waves cannot be considered as direct causes of morbidity or mortality, but are considered as aggravating 
factors in temperature-sensitive diseases development for vulnerable populations with a health background (Xu, 2012; Zeng, 2016).

\section{Conclusion}

Minimum and maximum temperatures are on an increasing trend in the northern part of Senegal with the years 2010, 2013, 2017 and 2018 considered as very hot with a large number of days with heat waves observed. This temperature upward combined with the rise in relative humidity tends to increase the heat felt sensation and the heat waves effect on populations health.

The frequency of heat waves recurrence resulted in a resurgence of certain diseases sensitive to the temperature increase leading to excess of morbidity and mortality with high frequentation of health facilities in the North and North-East departments of Senegal. The diseases concerned are mainly chronic diseases such as heart disease, diabetes, arterial hypertension, asthma, respiratory affections, hyperthermia, rheumatism, etc., which affect more people over 60 years and children under 14 years. The highest morbidity and mortality rates were recorded especially among elderly women during the severe heat wave episodes experienced especially in May 2013.

While there are many risk factors associated with morbidity and mortality related to the impact of heat waves, including housing conditions, lifestyles, socio-economic comfort level and types of activities, populations with a health background are mainly most exposed and vulnerable to rising temperatures.

However, the high vulnerability of the populations noted in these localities is not just related to the occurrence of extreme temperatures but also to other factors such as adaptation strategies or the responses of communities to the health impact of heat waves. Thus, the prevention of health problems related to rising temperatures requires the development of an early warning system for heat waves in order to strengthen the resilience of populations and the health system to the impacts of climate change.

\section{Declarations}

\section{Author's contribution}

IS, BC, BN, AAD, MT and JAN designed the study. IS, BC and BN coordinated the field data collection. BC, $M T$ and $B N$ did the statistical and geospatiale analysis. IS wrote the first draft of the manuscript. ON, MAS, BC, BN, AAD, YN, MT, DB, RL, SJ and JAN reviewed the manuscript. All authors read and approved the final version of the manuscript prior to submission.

\section{Ethical Approval}

This study obtained the approval of the National Health Research Ethical Committee of Senegal, which made it possible to collect health data from health centers and households.

\section{Consent to Participate}


An informed consent form was submitted to the selected households before the administration of the questionnaire and all the participants in the household survey signed the ethical clearance.

\section{Consent to Publish}

The authors consent to publsh their paper in the journal of Environmental Sciences and Pollution Research.

\section{Competing Interests}

The authors declare that there are no competing interests and then this specific section is not applicable.

\section{Availability of data and materials}

The data and materials from household surveyrs are available and could be uploaded.

\section{Funding}

This study was supported by funding from the Climate Research for Developpement (CR4D) from the African Academy of Sciences (AAS), the United Nations Economic Commission for Africa (UNECA) and the United Kingdom Aid (UKAID) through the Centre for Ecological Monitoring (CSE). The funder had no role in the study design, in the data collection and analyses or interpretation of the data, decision to publish or preparation of the manuscript.

\section{Acknowledgements}

The authors are grateful to all the populations of the northern Senegal who participated in this study and household's surveys. The authors also thank the staff of the health district of northern Senegal and the field enumerators for their support during data collection.

\section{References}

1. Anderson GB, Oleson KW, Jones B, Peng RD. Projected trends in high-mortality heatwaves under different scenarios of climate, population, and adaptation in 82 US communities. Clim Change, 2016. https://doi.org/10.1007/s10584-016-1779-x

2. ANSD. Recensement Général de la Population et de l'Habitat, de l'Agriculture et de l'Elevage (RGPHAE), Rapport final, 2013, 417 p.

3. Armstrong B. 2006. Models for the relationship between ambient temperature and daily mortality. Epidemiology 17:624 \pm 31 . 2006. https://doi.org/10.1097/01.ede.0000239732.50999.8f PMID: 17028505

4. Auger N, Fraser WD, Smargiassi A, Kosatsky T. Ambient Heat and Sudden Infant Death: A CaseCrossover Study Spanning 30 Years in Montreal, Canada. Environ Health Perspect. 2015 
Jul;123(7):712-6. doi: 10.1289/ehp.1307960. Epub 2015 Mar 6. PMID: 25748025; PMCID:

PMC4492261.

5. Baaghideh M, Mayvaneh F. Climate change and simulation of cardiovascular disease mortality: A case study of Mashhad, Iran. Iran J Pub Health 2017, 46:396 \pm 407.

6. Basu, R.; Samet, J.M. Relation between elevated ambient temperature and mortality: A review of the epidemiologic evidence. Epidemiol. Rev. 2002, 24, 190-202. [CrossRef]

7. Benmarhnia T, Sottile M-F, Plante C, Brand A, Casati B, Fournier M, et al. Variability in temperaturerelated mortality projections under climate change. Environ Health Perspect 2014, 122:1293 \pm 1298. https://doi.org/10.1289/ehp.1306954 PMID: 25036003

8. Besancenot, J P. La mortalité consécutive à la vague de chaleur de l'été 2003 : étude épidémiologique. Press therm $2005 ; 142: 13-24$.

9. Cadot E. et Spira. Canicule et surmortalité à Paris en août 2003. Espace populations sociétés, 2006/2-3 | 2006, 239-249.

10. Carlton, E.J.; Woster, A.P.; DeWitt, P.; Goldstein, R.S.; Levy, K. A systematic review and meta-analysis of ambient temperature and diarrhoeal diseases. Int. J. Epidemiol. 2016, 45, 117-130. [CrossRef] [PubMed]

11. Chen H, Wang J, Li Q, Yagouti A, Lavigne E, Foty R, Burnett RT, Villeneuve PJ, Cakmak S, Copes R. Assessment of the effect of cold and hot temperatures on mortality in Ontario, Canada: a populationbased study. CMAJ Open. 2016 Feb 2;4(1):E48-58. doi: 10.9778/cmajo.20150111. PMID: 27280114; PMCID: PMC4866918.

12. Cheng J, Xu Z, Zhu R, Wang X, Jin L, Song J, et al. Impact of diurnal temperature range on human health: a systematic review. Int J Biometeorol 58:2011 \pm 2024 . 2014. https://doi.org/10.1007/s00484014-0797-5 PMID: 24535132

13. Christensen, J.H., B. Hewitson, A. Busuioc, A. Chen, X. Gao, I. Held, R. Jones, R.K. Kolli, W.-T. Kwon, R. Laprise, V. Magaña Rueda, L. Mearns, C.G. Menéndez, J. Räisänen, A. Rinke, A. Sarr and P. Whetton,. Regional Climate Projections. In: Climate Change 2007: The Physical Science Basis. Contribution of Working Group I to the Fourth Assessment Report of the Intergovernmental Panel on Climate Change [Solomon, S., D. Qin, M. Manning, Z. Chen, M. Marquis, K.B. Averyt, M. Tignor and H.L. Miller (eds.)]. 2007, Cambridge University Press, Cambridge, United Kingdom and New York, NY, USA.

14. Corobov R, Sheridan S, Ebi K \& Opopol N. Warm Season Temperature-Mortality Relationships in Chisinau (Moldova). International Journal of Atmospheric Sciences. Volume 2013, Article ID 346024, 9 pages. http://dx.doi.org/10.1155/2013/346024

15. Diboulo E, Sié A, Rocklöv J, Niamba L, Yé M, Bagagnan C, Sauerborn R. Weather and mortality: a 10 year retrospective analysis of the Nouna Health and Demographic Surveillance System, Burkina Faso. Glob Health Action. 2012 Nov 23;5:6-13. doi: 10.3402/gha.v5i0.19078. PMID: 23195510; PMCID: PMC3508665.

16. Elisaveta P. Petkova, Radley M. Horton, Daniel A. Bader and Patrick L. Kinney. Projected Heat-Related Mortality in the U.S. Urban Northeast. Int. J. Environ. Res. Public Health 2013, 10, 6734-6747. 
17. Elliot, A.J.; Bone, A.; Morbey, R.; Hughes, H.E.; Harcourt, S.; Smith, S.; Loveridge, P.; Green, H.K.; Pebody, R.; Andrews, N.; et al. Using real-time syndromic surveillance to assess the health impact of the 2013 heatwave in England. Environ. Res. 2014, 135, 31-36. [CrossRef] [PubMed]

18. Fouillet, A.; Rey, G.; Laurent, F.; Pavillon, G.; Bellec, S.; Guihenneuc-Jouyaux, C.; Clavel, J.; Jougla, E.; Hemon, D. Excess mortality related to the August 2003 heat wave in France. Int. Arch. Occup. Environ. Health 2006, 80, 16-24. [CrossRef] [PubMed]

19. Green, R.S.; Basu, R.; Malig, B.; Broadwin, R.; Kim, J.J.; Ostro, B. The effect of temperature on hospital admissions in nine California counties. Int. J. Public Health 2010, 55, 113-121. [CrossRef] [PubMed]

20. Guo Y, Gasparrini A, Li S, Sera F, Vicedo-Cabrera AM, de Sousa Zanotti Stagliorio Coelho M,et al. Quantifying excess deaths related to heatwaves under climate change scenarios: A multicountry time series modelling study. PLoS Med, 2018, 15(7): e1002629.

https://doi.org/10.1371/journal.pmed.1002629

21. Guo Y, Li S, Liu DL, Chen D, Williams G, Tong S. Projecting future temperature-related mortality in three largest Australian cities. Environ Pollut 208:66 \pm 73.2016 . https://doi.org/10.1016/j.envpol.2015.09. 041 PMID : 26475058

22. Hémon $D$, Jougla E Estimation de la surmortalité et principales caractéristiques épidémiologiques. Surmortalité liée à la canicule d'août 2003 : rapport d'étape. [Rapport de recherche] Institut national de la santé et de la recherche médicale (INSERM). 2003, 58 p.,

23. Huang, W.; Kan, H.; Kovats, S. The impact of the 2003 heat wave on mortality in Shanghai, China. Sci. Total Environ. 2010, 408, 2418-2420. [CrossRef] [PubMed].

24. Johnson, H.; Kovats, R.S.; McGregor, G.; Stedman, J.; Gibbs, M.;Walton, H. The impact of the 2003 heat wave on daily mortality in England and Wales and the use of rapid weekly mortality estimates. Euro. Surveill. 2005, 10, 168-171. [PubMed].

25. Jones TS, Liang AP, Kilbourne EM, Griffin MR, Patriarca PA, Wassilak SG. Morbidity and mortality associated with the July 1980 heat wave in St Louis and Kansas City, Mo. JAMA 1982; 247(24):3327-31

26. Kovats RS, Kristie LE. Heatwaves and public health in Europe. Eur J Public Health. 2006 Dec;16(6):592-9. doi: 10.1093/eurpub/ckl049. Epub 2006 Apr 27. PMID: 16644927.

27. Li, M.; Gu, S.; Bi, P.; Yang, J.; Liu, Q. Heat waves and morbidity: Current knowledge and further direction-A comprehensive literature review. Int. J. Environ. Res. Public. Health 2015, 12, 52565283. [CrossRef] [PubMed].

28. MEDD-GCF 2020 : Programme Pays 2018-2030. Ministère de l'Environnement et du Développement Durable (MEDD) et Fonds Vert Climat (FVC). Rapport final, 124p.

29. mental Panel on Climate Change. Cambridge University Press; 2014. pp. 709-75

30. mental Panel on Climate Change. Cambridge University Press; 2014. pp. 709-754

31. Michelozzi, P.; De' Donato, F.K.; Bargagli, A.M.; D’Ippoliti, D.; De Sario, M.; Marino, C.; Schifano, P.; Cappai, G.; Leone, M.; Kirchmayer, U.; Ventura, M.; Di Gennaro, M.; Leonardi, M.; Oleari, F.; De Martino, A.; Perucci, C.A. Surveillance of Summer Mortality and Preparedness to Reduce the Health Impact of 
Heat Waves in Italy. Int. J. Environ. Res. Public Health 2010, 7, 2256-2273.

https://doi.org/10.3390/ijerph7052256

32. Murari KK, Ghosh S, Patwardhan A, Daly E, Salvi K. Intensification of future severe heat waves in India and their effect on heat stress and mortality. Reg Environ Change, 2015, 15:569 579 .

33. Musengimana, G.; Mukinda, F.K.; Machekano, R.; Mahomed, H. Temperature variability and occurrence of diarrhoea in children under five-years-old in Cape Town metropolitan sub-districts. Int. J. Environ. Res. Public Health 2016, 13, 859. [CrossRef] [PubMed]

34. Naumova, E.N.; Jagai, J.S.; Matyas, B.; DeMaria, A., Jr.; MacNeill, I.B.; Griffiths, J.K. Seasonality in six enterically transmitted diseases and ambient temperature. Epidemiol. Infect. 2007, 135, 281-292. [CrossRef]

35. New, M., Hewitson, B., Stephenson, D.B., Tsiga, A., Kruger, A., Manhique, A., Gomez, B., Coelho, C.A.S., Masisi, D.N., Kululanga, E., Mbambalala, E., Adesina, F., Saleh, H., Kanyanga, J., Adosi, J., Bulane, L., Fortunata, L., Mdoka, M.L., Lajoie, R. Evidence of trends in daily climate extremes over southern and west Africa. Journal of Geophysical Research Atmospheres 111 (D14), 2006. https://doi.org/10.1029/2005JD006289.

36. Nitschke M, Hansen A, Bi P, Pisaniello D, Newbury J, Kitson A, Tucker G, Avery J, Dal Grande E. Risk Factors, Health Effects and Behaviour in Older People during Extreme Heat: A Survey in South Australia. International Journal of Environmental Research and Public Health. 2013; 10(12):67216733. https://doi.org/10.3390/ijerph10126721

37. OMM. Vagues de chaleur et santé: guide pour l'élaboration de systèmes d'alerte. Collection(s) and Series: OMM (Organisation météorologique mondiale), No. 1142, ISBN (or other code): 2015, 978-9263-21142-2.

38. Pascal M, Retel O, Laaidi K, Ung A, Wagner V. Impact des vagues de chaleur sur les recours aux soins : une revue de la littérature. Bull Epidémiol Hebd. 2013;(28-29):341-7. http:// opac.invs.sante.fr/index.php?lvl=notice_display\&id=11608

39. Sanderson M, Arbuthnott K, Kovats S, Hajat S, Falloon P. The use of climate information to estimate future mortality from high ambient temperature: A systematic literature review. PLoS ONE 12 (7): 2017, e0180369. 35p. https://doi. org/10.1371/journal.pone.0180369.

40. Semenza JC, Rubin CH, Falter KH, Selanikio JD, Flanders D, Howe HL, et al. Heat related deaths

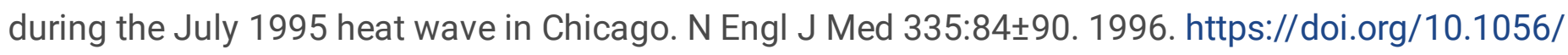
NEJM199607113350203 PMID: 8649494.

41. Smith K, Woodward A, Campbell-Lendrum D, Chadee D, Honda Y, Liu Q, et al. Chapter 11 - Human health: Impacts, Adaptation and Co-Benefits. In: Climate Change 2014: Impacts, Adaptation, and Vulnerability. Working Group II Contribution to the IPCC 5th Assessment Report [Final draft]. Intergovernmental Panel on Climate Change (IPCC), 2014, 70p.

42. Smith S, Elliot AJ, Hajat S, Bone A, Bates C, Smith GE, Kovats S. The Impact of Heatwaves on Community Morbidity and Healthcare Usage: A Retrospective Observational Study Using Real-Time 
Syndromic Surveillance. Int J Environ Res Public Health. 2016 Jan 16;13(1):132. doi:

10.3390/ijerph13010132. PMID: 26784214; PMCID: PMC4730523.

43. Smith, S.; Elliot, A.J.; Hajat, S.; Bone, A.; Smith, G.E.; Kovats, R.S. Estimating the burden of heat/sun stroke in England during the 2013 summer heatwave using syndromic surveillance. J. Epidemiol. Community Health 2015. [CrossRef]

44. Vandentorren S, Suzan F, Medina S, Pascal M, Maulpoix A, Cohen JC, Ledrans M. Mortality in 13 French cities during the August 2003 heat wave. Am J Public Health. 2004 Sep;94(9):1518-20. doi: 10.2105/ajph.94.9.1518. PMID: 15333306; PMCID: PMC1448485.

45. Xu Z, FitzGerald G, Guo Y, Jalaludin B, Tong S. Impact of heatwave on mortality under different heatwave definitions: A systematic review and meta-analysis. Environ Int, 2016, 89 \pm 90:193 \pm 203 .

46. Xu, Z.; Etzel, R.A.; Su, H.; Huang, C.; Guo, Y.; Tong, S. Impact of ambient temperature on children's health: A systematic review. Environ. Res. 2012, 117, 120-131. [CrossRef] [PubMed].

47. Zacharias, S.; Koppe, C.; Mucke, H.G. Influenza of heat waves on ischemic heart disease in Germany. Climate, 2014, 2, 133-152. [CrossRef].

48. Zeng Q, Li G, Cui Y, Jiang G \& Pan X. Estimating Temperature-Mortality Exposure-Response Relationships and Optimum Ambient Temperature at the Multi-City Level of China. Int. J. Environ. Res. Public Health 2016, 13, 279.

49. Zhang, Y., Li, S., Pan, X. et al. The effects of ambient temperature on cerebrovascular mortality: an epidemiologic study in four climatic zones in China. Environ Health 13, 24, 2014. https://doi.org/10.1186/1476-069X-13-24

\section{Figures}




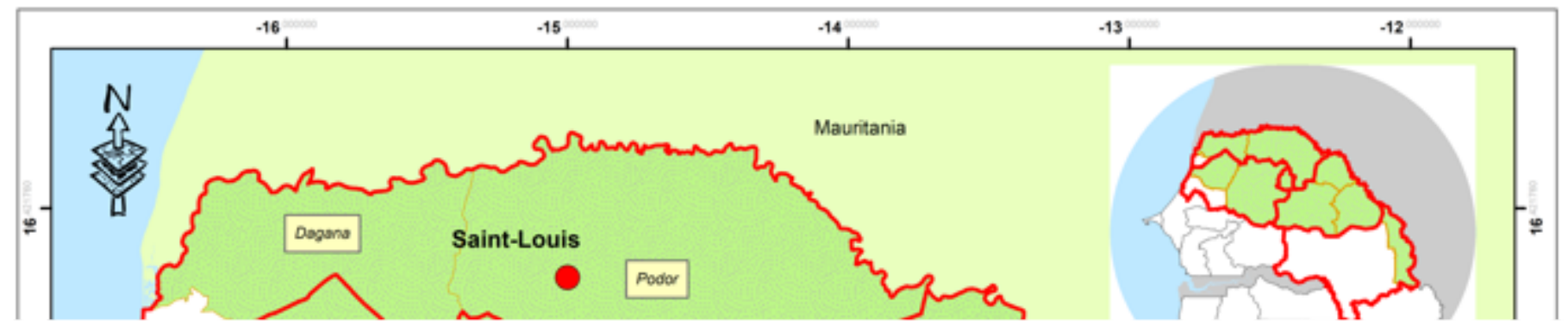

Figure 1

Location of the study area 


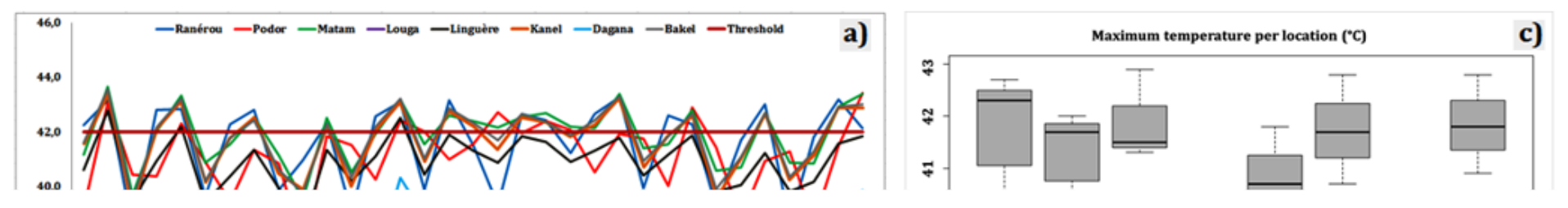

Figure 2

Variation of monthly maximum (a) and minimum (b) temperatures and corresponding boxplots ( $c$ and d) in April, May and June between 2009 and 2019. 

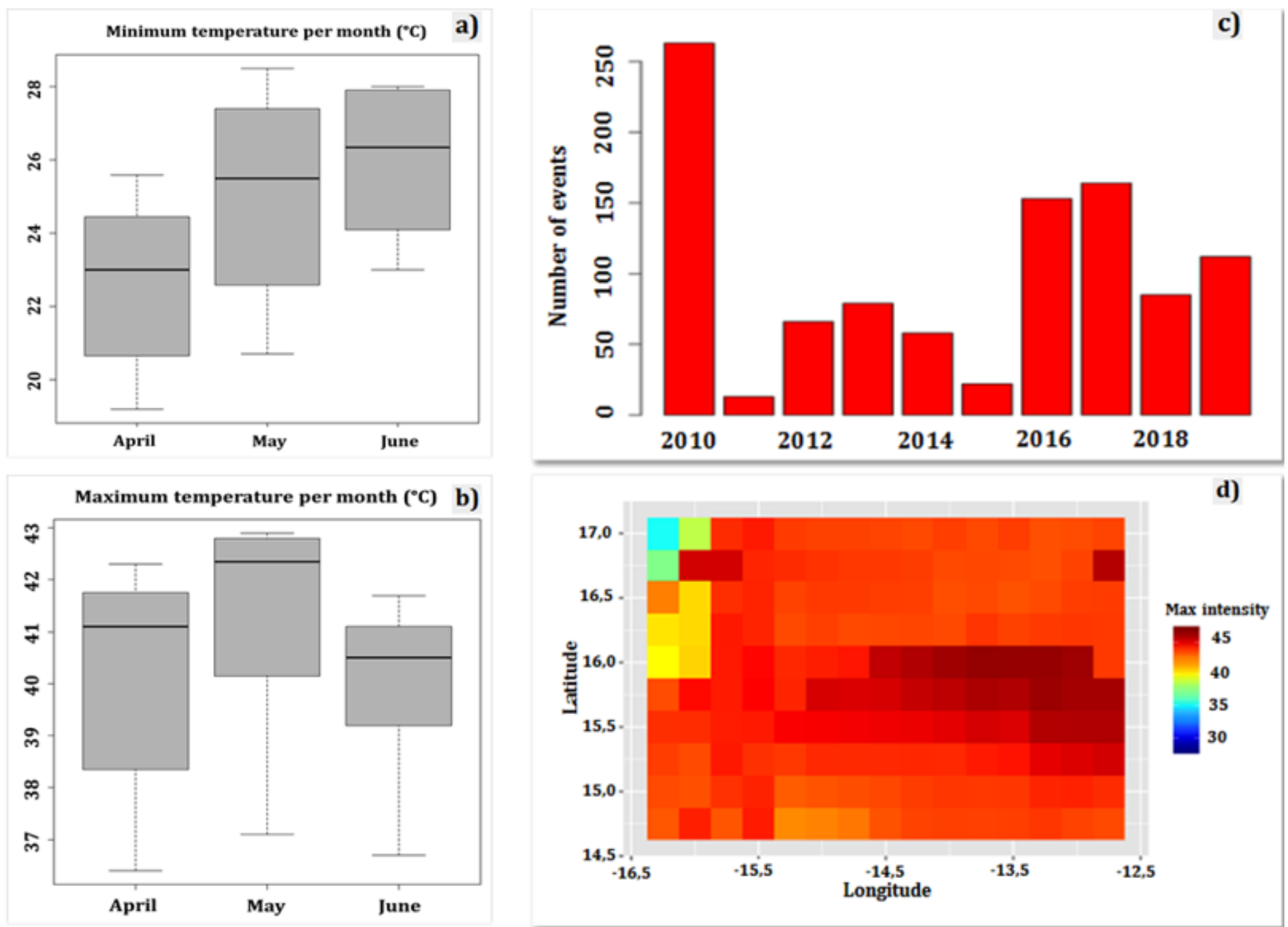

\section{Figure 3}

Heatwaves events during the period 2009 to 2019: (a) number of events (b) and their locations in terms of intensity; (c \& d) relative exposure level of localities and detection of the most exposed localities 


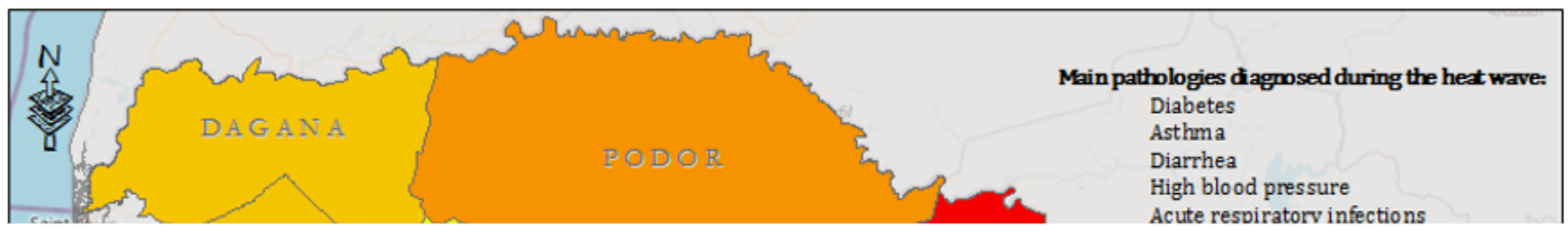

Figure 4

Cumulative cases of diagnosed morbidity from 2009 to 2019 and Prevalence of six temperature related diseases 


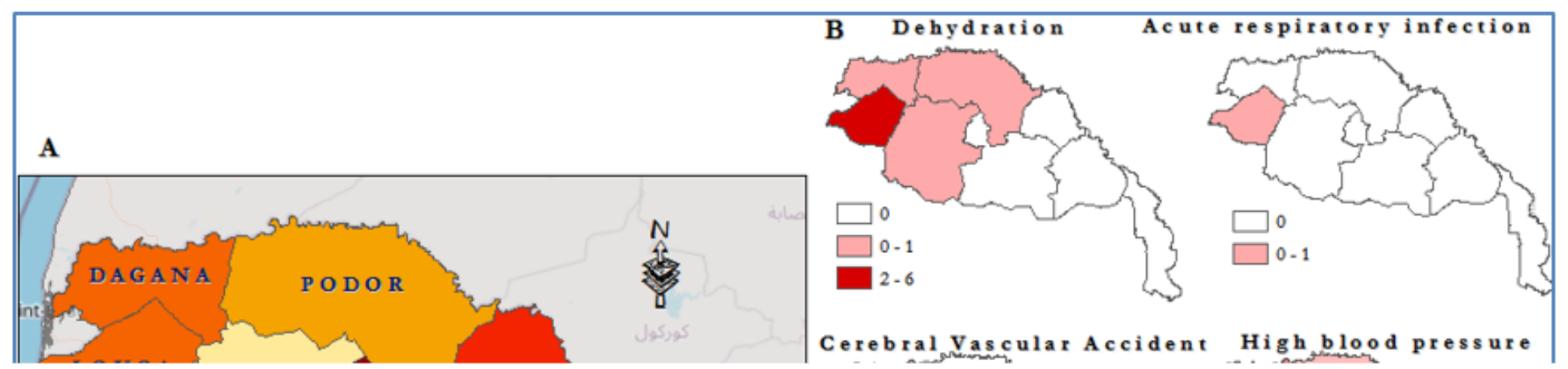

Figure 5

Morbidity and main diseases reported by households during heatwaves episodes 


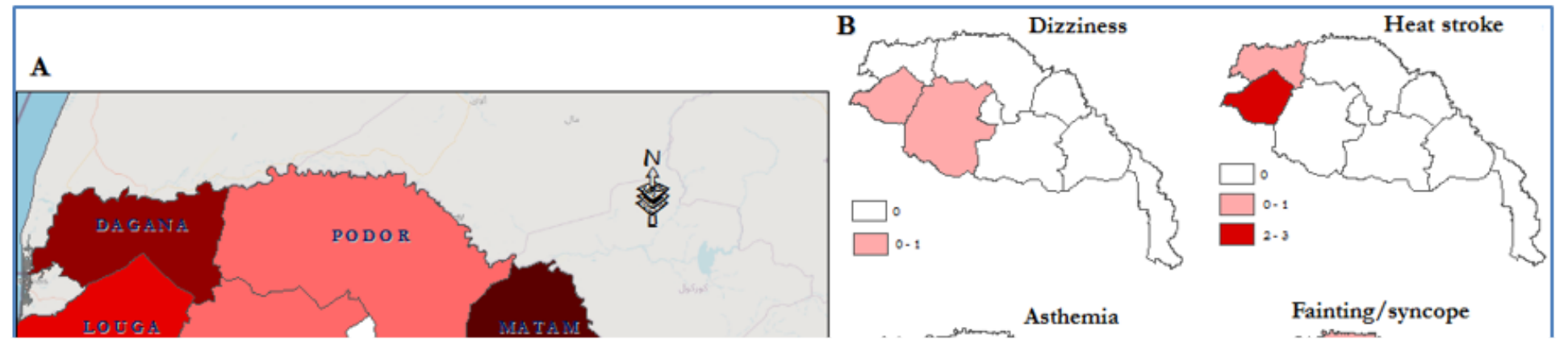

Figure 6

Distribution of deaths and major complaints

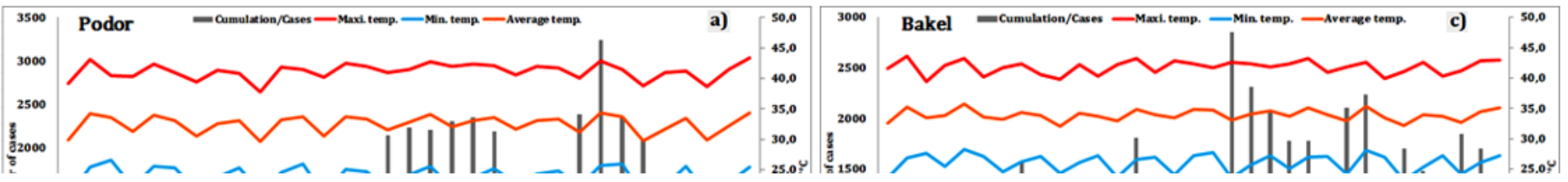


Figure 7

Relationship between cumulative pathology and temperature $\left({ }^{\circ} \mathrm{C}\right)$ : example of (a) Podor, (b) Ranerou, (c) Bakel and (d) Louga
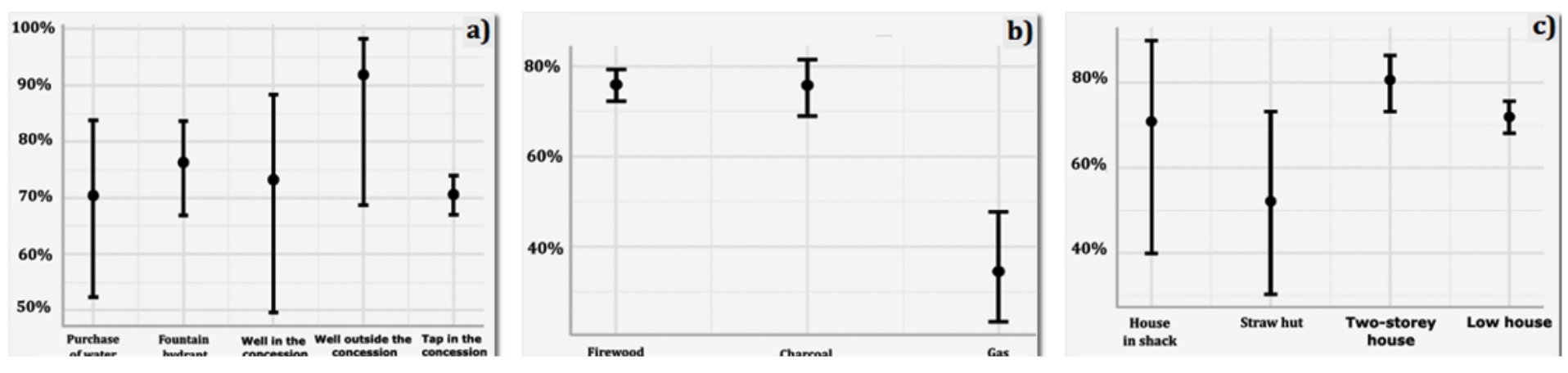

\section{Figure 8}

$(a, b, c, d, e)$ : Predicted values of the data subject in relation to social and environmental determinants 